\title{
Oral Verrucous Hyperplasia: A Case Series
}

\author{
${ }^{1}$ Mitesh N Jain, ${ }^{2}$ Shilpa Patel, ${ }^{3}$ Kamlesh Dekate, ${ }^{4}$ Jigna Pathak, ${ }^{5}$ Ketki J Shirke, ${ }^{6}$ Tanvi Patel
}

\begin{abstract}
Oral verrucous hyperplasia $(\mathrm{OVH})$ is a slow growing, soft tissue premalignant lesion which can transform into oral cancer. Areca-nut and quid use do seem to have a significant influence on the appearance of oral verrucous hyperplasia. Most frequently observed sites are buccal mucosa and lateral border of the tongue. OVH begins as a white plaque of hyperkeratosis known as plaque type variant which can get further transformed into mass type with less keratinization, exophytic growth and proliferative features thus leading to malignant transformation and poorer prognosis. This article describes series of cases which have been diagnosed histopathologically as verrucous hyperplasia with its clinical presentation and histopathological variants along with the criteria elaborated by different authors in establishing a diagnosis and a brief overview of the treatment modalities.
\end{abstract}

Keywords: Oral verrucous hyperplasia, Verrucopapillary lesions, Verrucous carcinoma, Verrucous hyperplasia.

How to cite this article: Jain MN, Patel S, Dekate K, Pathak J, Shirke KJ, Patel T. Oral Verrucous Hyperplasia: A Case Series. J Contemp Dent 2018;8(3):163-167.

\section{Source of support: Nil}

Conflict of interest: None

\section{INTRODUCTION}

Verrucous papillary lesions (VPLs) of the oral cavity are diagnostically challenging as they include a spectrum of benign, potentially malignant, and frankly malignant lesions. ${ }^{1}$ VPL clinically presents themselves as a greywhite, exophytic growth in gingiva, buccal mucosa or any other part of the oral cavity and histopathologically they may range from a simple hyperkeratotic lesion to verrucous hyperplasia, verrucous carcinoma or even frank squamous cell carcinoma. ${ }^{2}$

Oral verrucous hyperplasia $(\mathrm{OVH})$ is reclassified into "plaque" and "mass" variants while further stating that clinically both the variants can be called $\mathrm{OVH}$, but histopathologically only "mass" variant fits the bill to be called the same and "plaque" type lesions can be

\footnotetext{
1,5,6 Postgraduate Student, ${ }^{2}$ Professor and Head, ${ }^{3}$ Associate Professor, ${ }^{4}$ Professor

${ }^{1-6}$ Department of Oral Pathology and Microbiology, Mahatma Gandhi Mission's Dental College and Hospital, Kamothe, Navi Mumbai, India

Corresponding Author: Mitesh N Jain, Postgraduate Student, Department of Oral Pathology and Microbiology, Mahatma Gandhi Mission's Dental College and Hospital, Kamothe, Navi Mumbai, India, email id: miteshjn749@gmail.com
}

called an oral verruciform leukoplakia. ${ }^{3}$ Over some time, it has been observed that clinicians have found it difficult to distinguish verrucous hyperplasia from verrucous carcinoma due to its marked similarity in clinical appearance. Verrucous hyperplasia with the malignant potential of $3.1 \%$ over an average of 54.6 months is a high-risk lesion, ${ }^{4}$ along with the fact that it has coexisted with verrucous carcinoma in $29 \%$ of cases, and therefore makes it a lesion to be reckoned with. Various treatment modalities include surgery, chemotherapy, radiation or combinations of these and photodynamic therapy which has been recently reported.

Flowchart 1 depicting histogenesis of verrucous hyperplasia: ${ }^{5}$

Flow Chart 1: Histogenesis of verrucous hyperplasia

Epithelial hyperplasia comprised of acanthosis and broadening of rete ridges

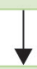

Epithelial cells most distant from the blood supply become edematous and swollen

Degeneration and necrosis of edematous and swollen cells

Necrotic cells desquamate, leaving clefts in the surface of epithelium

Verrucous projections supported by lamina propria form between the adjacent clefts

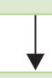

Verrucous projections and clefts undergo keratinization

\section{CASE SERIES}

Five cases of histopathologically diagnosed verrucous hyperplasia (Figs 1 to 4) from the year 2015 to 2016 have been retrieved from the archives of the Department of oral pathology and microbiology. Clinical and histopathological observations are summarized in Table 1.

\section{DISCUSSION}

Verrucous papillary lesions (VPLs) are a heterogeneous group of lesions, among which OVH has evoked considerable attention, as they have been found to be potentially malignant. Shear and Pindborg also observed difficulty in distinguishing verrucous hyperplasia $(\mathrm{VH})$ and verrucous carcinoma (VC) clinically, and they first reported 


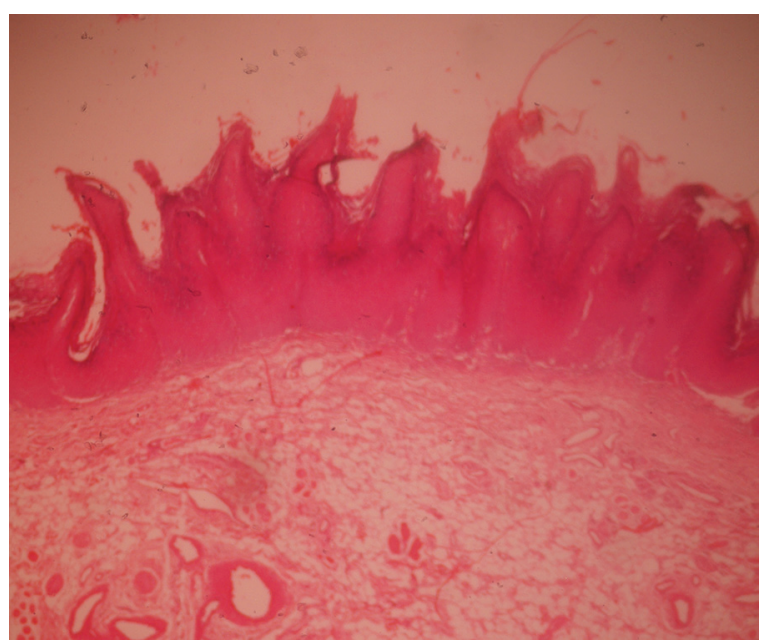

Fig. 1: Photomicrograph of mass-type OVH showing stratified squamous epithelium with verrucous surface depicting protruding masses of epithelial growth and minimal connective core tissues. (H \& E Stain, Magnification 40X)

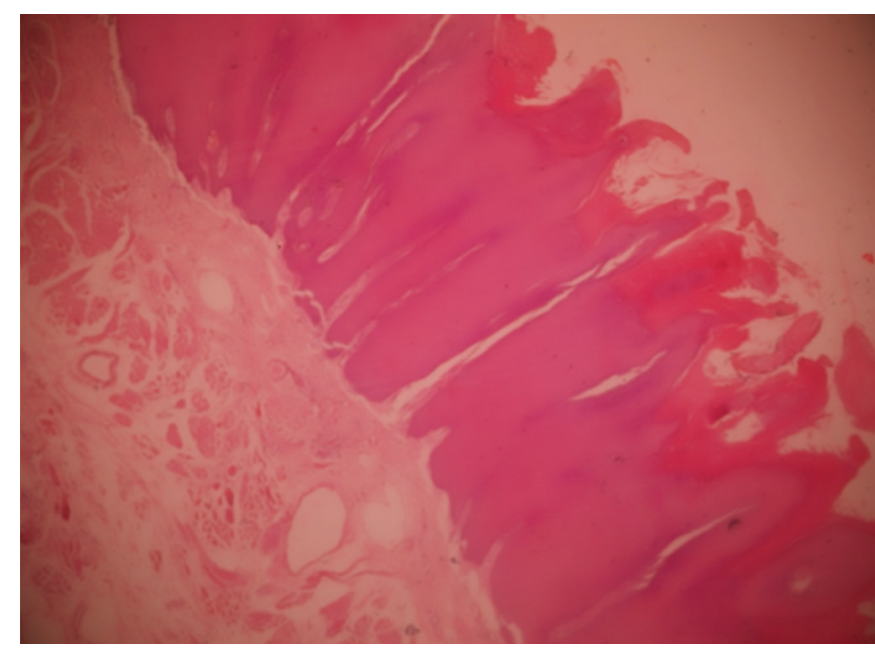

Fig. 3: Photomicrograph of plaque-type OVH showing stratified squamous epithelium with long, narrow rete-ridges. Heavy keratinization of verrucous processes is also evident in the present tissue section (H\&E Stain, magnification 40X)

a case of $\mathrm{OVH}$, on the basis of clinic-pathological description. ${ }^{5}$ This was also based on the fact that in their case series, there was the coexistence of verrucous hyperplasia and verrucous carcinoma which reinstated the need for adequate biopsy and histopathological diagnosis for a confirmatory diagnosis. In another study conducted, Murrah and Batsakis have confined OVH strictly to a histopathological entity, regarded it to be an irreversible. ${ }^{6}$ In our case series, we have observed a total of five cases of verrucous hyperplasia, out of which three were diagnosed as 'plaque' type and two cases as 'mass' type. All the cases observed had a habit of either chewing gutkha, betel nut, tobacco or cigarette smoking 3 to 5 times a day for over a period of 5 to 20 years which goes in tandem with the study conducted by Wang Yi et al wherein they found a high association of areca quid or cigarette smoking habit in verrucous hyperplasia almost to an extent of $90 \%{ }^{7}$ The lesion was found on the lateral border

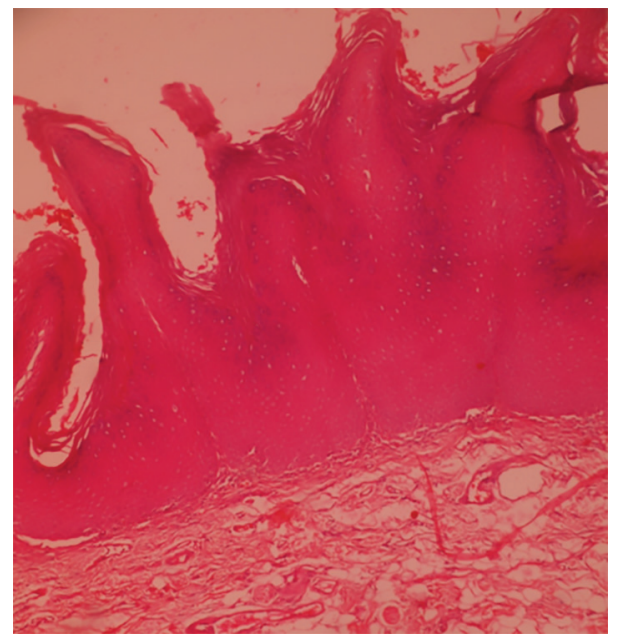

Fig. 2: Photomicrograph of mass-type OVH showing stratified squamous epithelium with broad, flat rete-ridges and less keratinization; (H \& E Stain, Magnification 100X)



Fig. 4: Photomicrograph of plaque-type OVH showing stratified squamous epithelium with long, narrow rete-ridges. Heavy keratinization of verrucous processes is also evident in the present tissue section (H\&E Stain, magnification 100X)

of the tongue for 'mass' type of verrucous hyperplasia whereas buccal mucosa was predominant site for 'plaque' type of verrucous hyperplasia. Hazarey et al in their study titled 'Verrucous Hyperplasia: A Clinic-pathologic Study' indicated buccal mucosa to be the most common site for verrucous hyperplasia; ${ }^{8}$ Wang et al. in their study 'Oral verrucous hyperplasia: Histologic classification, prognosis, and clinical implications' also agreed to this which was based on the fact that quid is usually placed in this region of mouth. ${ }^{7}$ This was in starking contrast with the findings of shear et al. who found gingiva and alveolar mucosa to be the most common sites for verrucous hyperplasia. ${ }^{5}$ The major histopathologic findings in our study were as follows; the two cases of 'mass' type showed parakeratinized epithelium whereas 'plaque' type showed both orthokeratinized and parakeratinized epithelium (Table 1). Keratin plugging was a superficial characteristic feature appreciated in all the three 'plaque' type cases 


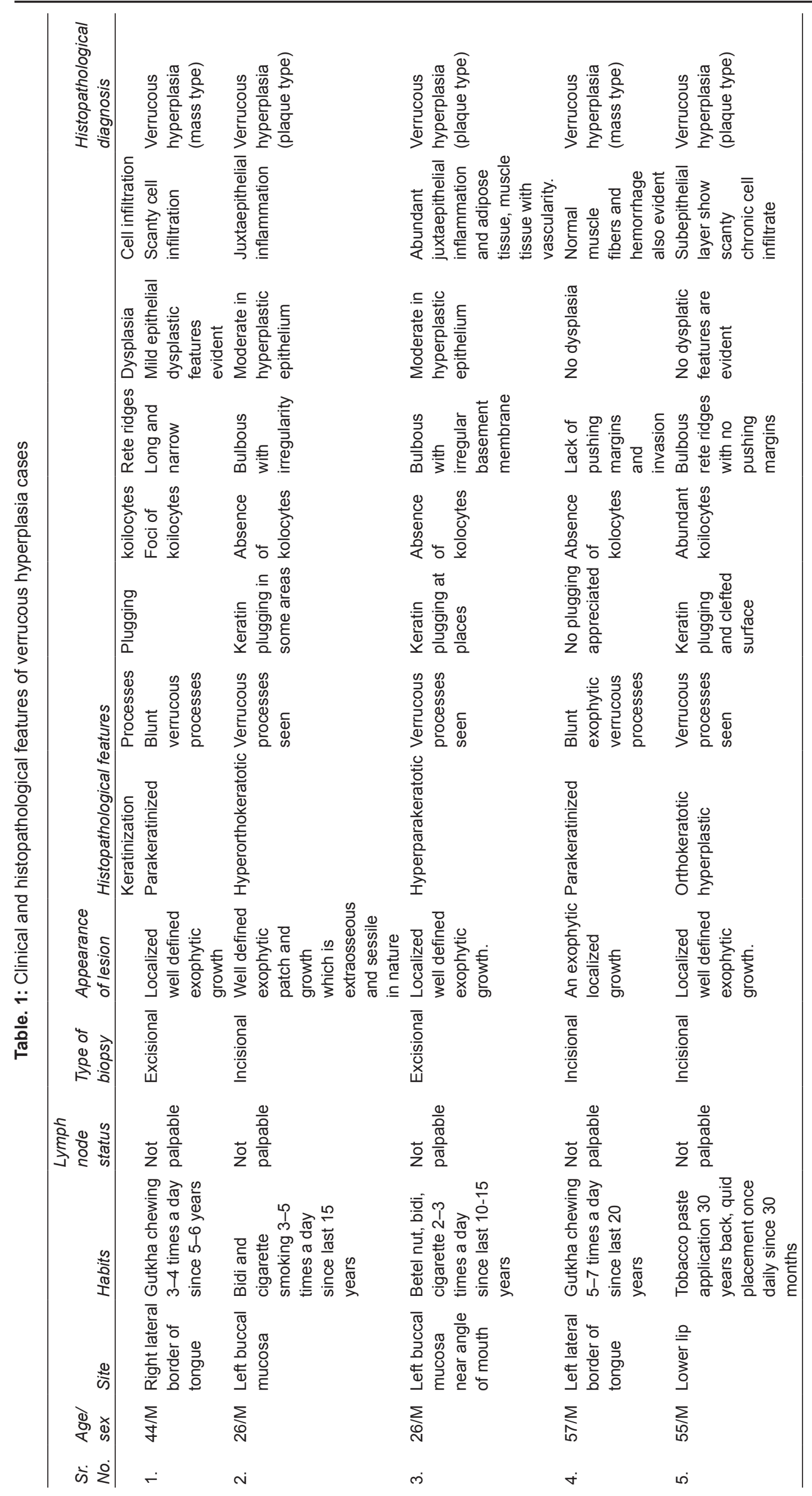


Table 2: Differences between mass type and plaque type of verrucous hyperplasia

\begin{tabular}{|c|c|c|}
\hline Parameter & Mass type & Plaque type \\
\hline Keratin thickness & $\begin{array}{l}\leq 40 \mu \mathrm{m} \text {; thin } \\
\text { surface }\end{array}$ & $\begin{array}{l}>40 \mu \mathrm{m} \text {; thick } \\
\text { surface }\end{array}$ \\
\hline $\begin{array}{l}\text { Malignant } \\
\text { transformation rate. }\end{array}$ & $\begin{array}{l}\text { Higher rate } \\
(17 \%)\end{array}$ & Lower rate $(03 \%)$ \\
\hline Mean age & $\begin{array}{l}\text { Higher mean } \\
\text { age of patients }\end{array}$ & $\begin{array}{l}\text { Compared with mass } \\
\text { type, mean age is } \\
\text { less }\end{array}$ \\
\hline Appearance & $\begin{array}{l}\text { Pink in } \\
\text { appearance }\end{array}$ & White in appearance \\
\hline
\end{tabular}

with thicker keratin surface thickness histopathologically; whereas 'mass' type showed thinner keratin surface thickness which categorized verrucous hyperplasia into plaque and mass type as given by Wang Yi et al. in their study surface keratin layer more than 40 micronmeter is classified as 'plaque' type and surface keratin layer less than that as 'mass' type (Table 2). The three 'plaque' type cases showed bulbous rete ridges, but all the five cases showed a lack of pushing margins or invasion which is a characteristic finding in verrucous hyperplasia, as studied by Slootweg and Muller in 1983, lack of pushing border or the absence of an endophytic growth helps in differentiating verrucous hyperplasia from other lesions of the spectrum. ${ }^{9}$ Focal areas or abundant koilocytes were seen in some cases. We also observed moderate dysplastic features in the epithelium of two 'plaque' type verrucous hyperplasia cases whereas one 'mass' type showed mild epithelial dysplastic features and one mass and one plaque type did not show any dysplasia. The connective tissue stroma of all the cases was showing mild scanty cell infiltrate, juxtaepithelial inflammation, normal muscle fibers, hemorrhage, and vascularity was evident. The diagnosis of this entity has been clouded in controversy, dissensions, and disputes over recent years, due to its similarity to verrucous carcinoma (VC), both clinically and histopathologically. Owing to its difficulty in identifying verrucous hyperplasia clinically and histopathologically; immunohistochemistry has come to play a big role as an adjunct to confirm verrucous hyperplasia. There are methods to identify verrucous hyperplasia immunohistochemically (Table 3). A panel of markers which includes Ki67, p53, E-cadherin and MMP1 were used in 28 cases of verrucous hyperplasia and 32 cases of verrucous carcinoma where Klieb and Raphael found that verrucous carcinoma stained more diffusely with p53 and Ki67 in the upper layers in relative comparison with verrucous hyperplasia. Also, $68.8 \%$ of cases showed staining for MMP1 in papillary layer of verrucous carcinoma as against $35.7 \%$ of verrucous hyperplastic cases. As verrucous hyperplasia $(\mathrm{VH})$ and verrucous carcinoma (VC) may present with similar clinical features, these entities need to be distinguished histologically. ${ }^{10}$
Table 3: Studies using immunoshitochemical markers as a differentiating factor between verrucous hyperplasia and verrucous carcinoma

\begin{tabular}{|c|c|c|c|}
\hline $\begin{array}{l}\text { Author and } \\
\text { year }\end{array}$ & Marker & $\begin{array}{l}\text { Verrucous } \\
\text { hyperplasia }\end{array}$ & $\begin{array}{l}\text { Verrucous } \\
\text { carcinoma }\end{array}$ \\
\hline \multirow[t]{4}{*}{$\begin{array}{l}\text { Benjamin } \\
\text { et al. }\end{array}$} & Ki67 & $\begin{array}{l}\text { Expression is } \\
\text { limited to basal } \\
\text { layer. }\end{array}$ & $\begin{array}{l}\text { Expression is seen } \\
\text { in basal as well as } \\
\text { supra-basal layer. }\end{array}$ \\
\hline & P53 & $\begin{array}{l}\text { Absence of } \\
\text { expression }\end{array}$ & $\begin{array}{l}\text { Expression is seen } \\
\text { in basal as well as } \\
\text { supra-basal layer. }\end{array}$ \\
\hline & MMP1 & $\begin{array}{l}\text { Shows a lack } \\
\text { of expression } \\
\text { in underlying } \\
\text { stromal cells. }\end{array}$ & $\begin{array}{l}\text { Shows expression } \\
\text { in underlying } \\
\text { stromal cells as } \\
\text { well as in the } \\
\text { epithelium. }\end{array}$ \\
\hline & E-cadherin & Diffused staining & Diffused staining \\
\hline \multirow[t]{4}{*}{ Lin et al. } & MDM2 & $\begin{array}{l}\text { Diffuse and } \\
\text { strong nuclear } \\
\text { staining seen in } \\
\text { both basal and } \\
\text { parabasal layer. }\end{array}$ & $\begin{array}{l}\text { In addition to basal } \\
\text { and parabasal } \\
\text { layer, nuclear } \\
\text { staining of MDM2 } \\
\text { was also seen in } \\
\text { spinous layer. }\end{array}$ \\
\hline & HSP70 & $\begin{array}{l}\text { Expressed in } \\
\text { cytoplasm of } \\
\text { parabasal and } \\
\text { spinous cells. }\end{array}$ & $\begin{array}{l}\text { Expressed in } \\
\text { cytoplasm of } \\
\text { parabasal and } \\
\text { spinous cells. }\end{array}$ \\
\hline & P53 & $\begin{array}{l}\text { Positivity in } 06 \\
\text { out of } 27 \text { cases }\end{array}$ & $\begin{array}{l}\text { Positivity in } 09 \text { out } \\
\text { of } 27 \text { cases }\end{array}$ \\
\hline & $\mathrm{P} 21$ & $\begin{array}{l}\text { Lower mean } \\
\text { lablelling index } \\
\text { (LI) of } 11 \%\end{array}$ & $\begin{array}{l}\text { Lower mean } \\
\text { lablelling index (LI) } \\
\text { of } 07 \%\end{array}$ \\
\hline Paral et al. & $\begin{array}{l}\text { Alpha-SMA } \\
\text { and CD34 }\end{array}$ & $\begin{array}{l}\text { Increase of } \\
\text { CD34 along with } \\
\text { loss of alpha- } \\
\text { SMA indicates } \\
\text { towards } \\
\text { verrucosu } \\
\text { hyperplasia. }\end{array}$ & $\begin{array}{l}\text { Increase of } \\
\text { alpha-SMA with } \\
\text { loss of CD34 } \\
\text { indicates verrucous } \\
\text { carcinoma. }\end{array}$ \\
\hline
\end{tabular}

Also, a combined pattern of two more markers were sought for distinguishing verrucous hyperplasia (VH) from verrucous carcinoma (VC) (Table 3) wherein it was observed that gain of alpha-SMA along with loss of CD34 dendritic cells indicates towards verrucous carcinoma (VC) whereas gain of CD34 along with loss of alpha-SMA indicates a diagnosis of verrucous hyperplasia which made them suggest that both these lesions are separate entities owing to different stromal reactions. ${ }^{11}$

\section{Treatment}

Total surgical excision has been the conventional mode of treatment for oral verrucous hyperplasia. Transformation and recurrence to either squamous cell carcinoma or verrucous carcinoma have been reported after surgical intervention, but this has been due to non-adherence to strict guidelines and criteria for surgery. To avoid local recurrence, wide surgical excision of the primary verrucous lesion with adequate mucosal and soft tissue margin is necessary. ${ }^{1}$ Out of the five cases that we had, two cases 
were treated with wide excisions and the rest three were incisional biopsies. In terms of treatment modality, wide surgical excision of the lesion with adequate adjacent soft tissue margins to avoid recurrence with strict follow-up is the choice of treatment. However, the use of photodynamic therapy (PDT) is another effective treatment option for human premalignant and malignant lesions, because it is noninvasive, is well tolerated by patients, can be used repeatedly without cumulative side effects, and results in little scar formation. Two studies have shown that topical 5-aminolevulinic acid-mediated photodynamic therapy (ALA-PDT) can be used successfully for the treatment of OVH. ${ }^{12}$ Though it is not difficult to diagnose verrucous lesion on the basis of their verrucous surface clinically, it is crucial that biopsies of verrucous lesions include a lesional margin with adequate depth to get to a confirmatory diagnosis as verrucous hyperplasia has been seen coexisting with other lesions of the spectrum and more so, with the recent study where it was observed that delay in treatment for the 'mass' type eventually leads to malignancy with a malignant transformation rate of $17 \%$ as compared to the plaque type which showed a malignant transformation rate of $3 \%^{7}$ (Table 2).

\section{CONCLUSION}

It is evident from our case series that clinical diagnostic confusion still exists when it comes to VPL. To distinguish verrucous carcinoma from verrucous hyperplasia (plaque and mass type) histologically, it is necessary to include normal epithelium to ensure the right diagnosis. As it has malignant transformation potential, patients have to be treated in a manner similar to verrucous carcinoma.

\section{REFERENCES}

1. Kallarakkal TG, Ramanathan A, Zain RB. Verrucous papillary lesions: Dilemmas in diagnosis and terminology. International journal of dentistry. 2013;2013.

2. Zain R, Kallarakkal T, Ramanathan A, Kim J, Tilakaratne WM, Takata T et al. Exophytic Verrucous Hyperplasia of the Oral Cavity - Application of Standardized Criteria for Diagnosis from a Consensus Report. Asian Pacific Journal of Cancer Prevention 2016;17(9):4491-4501

3. Patil S, Warnakulasuriya S, Raj T, Sanketh DS, Rao RS. Exophytic oral verrucous hyperplasia: a new entity. Journal of investigative and clinical dentistry. 2016 Nov;7(4):417-423.

4. Grover S, Jha M, Sharma B, Kapoor S, Mittal K, Parakkat NK, Shivappa AB, Kaur R. Verrucous Hyperplasia: Case report and differential diagnosis. Sultan Qaboos University Medical Journal. 2017 Feb;17(1):e98.

5. Shear M, Pindborg JJ Verrucous hyperplasia of the oral mucosa. Cancer. 1980;46:1855-1862.

6. Murrah VA, Batsakis JG. Proliferative verrucous leukoplakia and verrucous hyperplasia. Ann Otol Rhinol Laryngol. 1994;103:660-663.

7. Wang YP, Chen HM, Kuo RC, Yu CH, Sun A, Liu BY, Kuo YS, Chiang CP. Oral verrucous hyperplasia: histologic classification, prognosis, and clinical implications. Journal of Oral Pathology \& Medicine. 2009 Sep;38(8):651-656.

8. Hazarey V, Ganvir S, Bodhade A. Verrucous hyperplasia: A clinico-pathological study. J Oral Maxillofac Pathol. 2011 May-Aug; 15(2): 187-191.

9. Slootweg PJ, Muller H. Verrucous hyperplasia or verrucous carcinoma: An analysis of 27 patients. J Maxillofac Surg. 1983;11(1):13-19.

10. Klieb H, Raphael SJ. Comparative study of the expression of P53, Ki67, E-cadherin and MMP-1 in verrucous hyperplasia and verrucous carcinoma of the oral cavity. Head Neck Pathol. 2007 Dec; 1(2):118-122.

11. Paral KM, Taxy JB, Lingen MW. CD34 and smooth muscle actin distinguish verrucous hyperplasia from verrucous carcinoma. Oral surgery, oral medicine, oral pathology and oral radiology. 2014;117(4):477-482.

12. Chang Y, Yu C. Successful treatment of a large oral verrucous hyperplasia with photodynamic therapy combined with cryotherapy. Journal of Dental Sciences. 2013(8):87e90. 